\title{
Estudo Retrospectivo da Prova de Trabalho de Parto na Viabilização do Parto Vaginal em Gestantes com uma Cesárea Anterior
}

\author{
Autora: Jacqueline Leite Frade \\ Orientadora: Prof ${ }^{\mathrm{a}}$. Dr ${ }^{\mathrm{a}}$. Iracema de Mattos Paranhos Calderon
}

Dissertação apresentada ao curso de pós-graduação em Ginecologia e Obstetrícia, Área de Concentração em Obstetrícia da Faculdade de Medicina de Botucatu - UNESP, para a obtenção do título de Mestre, em 9 de junho de 2000.

Objetivo: Estudar a validade da Prova de Trabalho de Parto (PTP) na viabilização do parto vaginal em gestantes com uma cesárea anterior.

Sujeitos e Métodos: Estudo retrospectivo, tipo coorte, no qual foram incluídas 438 gestantes com uma cesárea anterior ao parto em estudo e seus 450 recém-nascidos, atendidos num Serviço Terciário, nos dois últimos anos. O conjunto mãe - recém-nascido foi subdividido em dois grupos, considerando-se a PTP como variável independente. O tamanho amostral mínimo calculado foi de 121 gestantes/grupo. Como variáveis dependentes, foram avaliados a ocorrência de parto vaginal, os fatores relacionados à indicação da prova e a freqüência de complicações maternas e perinatais. Resultados e Conclusões: A PTP viabilizou o parto vaginal em 59,2\% das gestantes. Foi contra-indicada nas mais idosas $(\mathrm{OR}=0,93$; $\mathrm{IC}=0,910-0,972)$ e realizada na ausência de patologias intercorrentes $(\mathrm{OR}=3,20$; $\mathrm{IC}=2,014-5,100)$. A PTP preveniu as complicações respiratórias neonatais $(\mathrm{OR}=1,92 ; \mathrm{IC}=1,208-3,071)$ e não influenciou nos indices de morbimortalidade materna e perinatal. As complicações maternas foram relacionadas à via de parto - a cesárea aumentou o risco em três vezes $(\mathrm{OR}=3,53 ; \mathrm{IC}=1,574-7,935)$. A morbimortalidade perinatal dependeu do menor peso dos recém-nascidos e das malformações. Os resultados ratificam a validade da PTP em gestantes com uma cesárea anterior, mostrando-se estratégia segura na assistência ao parto dessas gestantes.

Palavras-chave: Prova de trabalho de parto. Cesárea. Morbidade perinatal.

\section{Impacto da Ação Educativa sobre a Taxa de Abandono do Serviço de Esterilidade Conjugăal da UNICAMP}

Autora: Sílvia Lucchini Joly De Mattos

Orientadores: Prof. Dr. Carlos Alberto Petta e Prof. Dr. Luis Guillermo Bahamondes

Dissertação de Mestrado apresentada ao Curso de Pós-Graduação em Tocoginecologia da Faculdade de Ciências Médicas da Universidade Estadual de Campinas para obtenção do Título de Mestre em Tocoginecologia, em 4 de fevereiro de 2000.

O objetivo deste estudo foi avaliar o impacto do programa de ação educativa em esterilidade na redução das taxas de abandono do serviço, na área de Esterilidade Conjugal da UNICAMP. Foi realizado um estudo retrospectivo do tipo pesquisa operacional, comparando a taxa de abandono do serviço antes e após o início do programa de ação educativa. Foram selecionadas as fichas de 167 casais antes da introdução da ação educativa no serviço, e outras 167 após o início deste programa. Foram avaliados dados como a idade e escolaridade da mulher e do homem, distância da residência, tipo e tempo de esterilidade, número de filhos da mulher e do homem com outro(a) parceiro(a) e da mulher com o parceiro atual, fatores etiológicos femininos e masculinos, e o abandono do serviço, incluindo o momento do acompanhamento em que ele ocorreu. A taxa de abandono no primeiro grupo foi de $70,7 \%$, e no segundo grupo de $61,7 \%$, não tendo sido observada diferença estatisticamente significativa entre os dois grupos. Verificou-se que a maior taxa de abandono ocorreu entre casais com a propedêutica incompleta de esterilidade. Foram encontradas como variáveis preditoras de abandono do serviço, a baixa idade da mulher e o baixo nível de escolaridade do casal. A ação educativa não pareceu ser, portanto, uma intervenção de maior relevância para o abandono do serviço, já que foram encontrados fatores mais importantes, como a baixa idade da mulher e o baixo nivel de escolaridade do casal, que pode refletir indiretamente o seu baixo nivel socioeconômico.

Palavras-chave: Infertilidade. Orientação pós-consulta. 